\title{
PROCESOS SENSORIALES Y EMOCIONALES IMPLICADOS EN LA ACTITUD SOLIDARIA
}

\section{SENSORY AND EMOTIONAL PROCESSES INVOLVED IN SOLIDARY ATTITUDE}

\author{
Ramón Rosal Cortés \\ Instituto Erich Fromm de Psicoterapia Integradora Humanista. Barcelona, España \\ ORCID: https://orcid.org/0000-0001-8378-2682
}

Cómo referenciar este artículo/How to reference this article:

Rosal Cortés, R. (2019). Procesos Sensoriales y Emocionales implicados en la Actitud Solidaria. Revista de Psicoterapia, 30(113), 179-196. https://doi.org/10.33898/rdp.v30i113.308

\begin{abstract}
Resumen
El presente trabajo se centra en el estudio de la relevancia de las primeras fases del ciclo del fluir vital de la Psicoterapia Integradora Humanista (Gimeno-Bayón y Rosal, 2016, 2017), y en concreto de la sensibilidad y la emoción, para la vivencia sana de la actitud de solidaridad para la justicia. En él tiene muy en cuenta - a modo de prólogo- la dimensión psicológica y ética del Movimiento de los Indignados, así como las reflexiones sobre el mismo del sociólogo Castells (2005, 2006, 2013). Tras subrayar la contribución de lo sensorial y afectivo para generar la experiencia que llevará a la persona a adopción de una ética solidaria, se describen, los principales trastornos de aquellas fases que la obstaculizan. La descripción contemplará los problemas que llevan a bloquearla, distorsionarla o dispersarla, haciéndola ineficaz. También se ocupa de las consecuencias a que darán lugar estas primeras fases cuando repercutan en la fase valorativa. Termina con la enumeración de los requisitos para transformar las experiencias sensibles y emocionales en una praxis efectiva, y la esperanza de que se pueda contribuir a ella desde la práctica psicoterapéutica.

Palabras clave: solidaridad para la justicia, ciclo del fluir vital, psicoterapia integradora humanista, sensibilidad, afectividad.
\end{abstract}

\begin{abstract}
This work focuses on the study (The aim of this paper is to analyze) the relevance of the first phases of the vital flow cycle of Humanist Integrative Psychotherapy (Gimeno-Bayon \& Rosal, 2016; 2017), and particularly of sensitivity and emotion, for the healthy living of the attitude of solidarity for justice. In this paper he takes very much into account -as a prologue- the psychological and ethical dimension of Indignados movement, as well as the considerations about it by the sociologist Castells (2005, 2006, 2013). After emphasize the contribution of the sensorial and affective dimension to generate the experience that will lead the person to adopt a solidarity ethic, the main disorders of those phases that hinder it are described. The description will contemplate the problems that lead to blocking, distorting or dispersing it, making it ineffective. The description also deals the consequences that will lead to these first phases when they affect the valuation phase. Finally, it ends with an enumeration of the requirements to transform sensitive and emotional experiences into an effective praxis, and the hope that it can be contributed to it from psychotherapeutic practice.
\end{abstract}

Keywords: solidarity for justice, cycle of vital flow, Humanistic Integrative Psychotherapy, sensitivity, affectivity.

Fecha de recepción: 15 de abril de 2019. Fecha de aceptación: 21 de mayo de 2019.

Correspondencia sobre este artículo:

E-mail: ramonrosalc@gmail.com

Dirección postal: c. Madrazo 113, enlo. 2ª 08021 Barcelona. España

(C) 2019 Revista de Psicoterapia 
El sociólogo Manuel Castells, es profesor de Sociología y Urbanismo en la Universidad de California en Berkeley y asimismo director del Internet Interdisciplinary Institute en la Universitat Oberta de Catalunya. Es el académico más citado del mundo en Tecnologías de la Información y la Comunicación, y el quinto académico más citado en Ciencias Sociales. Pero lo que aquí importa señalar principalmente es que se puede considerar como el principal investigador científico del Movimiento de los Indignados. Un precedente de esta tarea suya fue una experiencia importante que vivió en el año 1968, cuando era el profesor más joven de la Universidad de París, a los 24 años. Fue en sus clases donde un grupo de sus alumnos, entre los cuales se encontraba Daniel Cohn-Bendit, iniciaron el movimiento del Mayo francés de 1968. Esto tuvo como consecuencia su expulsión de París y su traslado a los Estados Unidos. Es a partir de este momento cuando se concentró en la investigación sobre el desarrollo de las tecnologías de la información y su impacto social. En su importante trilogía La Era de la Información, traducida a varios idiomas, tiene presentes las explicaciones sociológicas sobre la sociedad industrial que habían presentado anteriormente, entre otros, Max Weber y Marx. Aunque al inicio de los años 80 Castells ya se había distanciado de la influencia del segundo.

De sus más de veinte libros, casi todos traducidos a varios idiomas, y que han dado pie a que se le concediesen doctorados honoris causa en sucesivas universidades, el que aquí se tendrá presente es uno publicado en 2012 con el título -en la edición española- Redes de esperanza e indignación. En él ofrece la mejor investigación realizada hasta hoy sobre la influencia que estas redes han ejercido en el Movimiento de los Indignados en diversos países, inicialmente en países islámicos. Se informa sobre cómo han causado cambios que constituyen auténticas revoluciones pacíficas, aunque a veces grupos minoritarios violentos hayan podido deteriorar algo su estilo. Países como Túnez y Egipto, entre otros, sometidos desde hacía décadas a gobiernos dictatoriales, han tratado de implantar regímenes democráticos. A continuación el Movimiento de Indignados, gracias al apoyo de esas redes sociales, y de la eficacia de la comunicación digital, suscitó actuaciones multitudinarias en países del Primer Mundo, entre ellos: Inglaterra, Estados Unidos y España. Respecto a lo ocurrido en este último, Castells, escribiendo en el período de plena crisis, afirmó:

"España es el país de Europa donde el sistema político ha mostrado menos sensibilidad ante la protesta, y con los dos grandes partidos de acuerdo en ignorarla. El caso más dramático es el de las hipotecas. Los suicidios han disparado la alarma social, pero hace más de un año y medio que viene planteándose sin respuesta. La opinión pública ha registrado las críticas del 15-M. Las encuestas señalan un $70 \%$ de apoyo, pero también registran que apenas se cree que haya capacidad de cambio. Ha cambiado la conciencia de la gente, pero el sistema político se mantiene imperturbable. Y esto puede degenerar en enfrentamientos y en violencia [...] Con una sociedad 
movilizada indignada, sin respuesta institucional creíble, es difícil evitar la violencia" (Castells, Entrevista en El País, 19-12-2012).

Castells destaca lo ocurrido en Islandia como la revolución pacífica con mayores consecuencias profundas en la transformación de las estructuras sociales, políticas y económicas, a partir de una elevada toma de conciencia democrática por parte de la generalidad de los ciudadanos. "En Islandia se nacionalizaron los bancos, se echó a los dos partidos que la gobernaban desde 1927, se creó un nuevo gobierno con democracia participativa, se elaboró una nueva constitución debatida por internet con miles de ciudadanos interviniendo" (Castells, ibidem).

No se puede decir que el Movimiento de los Indignados se limitara a protestar contra lo existente en las estructuras económicas y políticas y en la forma irresponsable o incompetente de actuar los principales responsables de ellas. Principalmente se protestó por el funcionamiento actual del sistema financiero (aunque solo una parte de los seguidores era anticapitalista, había unanimidad respecto a este rechazo). Pero, a continuación, presentó propuestas razonables para la solución de esos problemas: "es sobre todo un movimiento político que exige la democracia real". Para España presentó "propuestas positivas: la reforma de la ley electoral, la modificación del sistema hipotecario y mecanismos de control sobre la banca" (Ibidem).

Algunos datos y conclusiones que pueden deducirse de las declaraciones de este reconocido sociólogo son:

a) En el inicio del Movimiento de los Indignados han tenido lugar-en cada uno de los implicados-experiencias sensoriales. Los que hayan cerrado los ojos y/o los oídos a ellas habrán impedido su movilización para implicarse. Algunas de ellas son:

- Ver el cuerpo de un suicidado por desesperación. Verlo directamente, o por internet, o por visualización mental tras recibir la información. En España la ley de hipotecas ha ocasionado sucesivos suicidios.

- Ver y leer gran cantidad de mensajes por internet de testigos de sucesos y situaciones injustas.

- Comprobar sensorialmente, en ocasiones de concentraciones multitudinarias que son muchos los que comparten las mismas experiencias. Ver los mensajes de sus carteles y oír las exclamaciones y gritos de protesta.

Los obreros se comunican en las fábricas, los jóvenes de hoy lo hacen en internet, pero es vital que luego ocupen el espacio público. Al ocupar un espacio público, la gente se da cuenta de que existe y de que puede imponer su derecho a la ciudad por encima de las reglas de tráfico. Lo que produce los cambios históricos es la combinación de un espacio de comunicación, un espacio de reunión, un espacio de incidencia política [...] Los movimientos nacen en la red y se organizan en el espacio urbano (Ibidem).

Gracias a estas concentraciones multitudinarias los procesos sensoriales de la 
mirada y la escucha son profundamente estimulados. La fase inicial del ciclo del fluir vital del modelo de la Psicoterapia Integradora Humanista (vid. GimenoBayón y Rosal, 2016, 2017), la receptividad sensorial, puede almacenar una gran cantidad de información. En cambio, la población -sea juvenil o adulta- que se ha mantenido al margen de esas imágenes y sonidos -tanto por no escucharlas y contemplarlas en internet, como por no acudir a los espacios públicos-no dispondrá de esa base sensorial movilizadora. Requerirá mucha más capacidad imaginaria e inteligencia emocional para hacerse cargo de lo que ocurre.

a) A partir de la receptividad sensorial respecto a esa información -o simultáneamente- la persona con un fluir emocional sano (sin bloqueos, ni dispersiones, ni distorsiones) experimenta vivencias emocionales profundas, de sentimientos y emociones diversas.

La primera emoción que aparece es la indignación. El miedo atenaza a la gente. Miedo a perder lo poco que queda. El miedo y la resignación paralizan a la gente. Esto salta cuando no se puede más. En ese momento se supera el miedo. La esperanza llega cuando superas el miedo y encuentras en las redes, en la calle, mucha gente que está como tú. Empieza al hablar con otro, al sentir con otro. Al percibir que no tenemos el poder pero estamos juntos, y tenemos la razón con nosotros. Ese es el paso del miedo a la esperanza (Ibidem).

Sin haberse podido vivir estas experiencias sensoriales y emocionales no se habrían producido las transformaciones sociales en varios países islámicos, y en Islandia, y la creciente toma de conciencia de muchos ciudadanos europeos y americanos.

Está claro que no todo se reduce a un buen fluir de los procesos sensoriales y emocionales, pero estos cumplen la función básica de informar -e impactar, si es preciso- para orientar la acción. Luego vienen las intuiciones y reflexiones de una buena inteligencia emocional, la captación intuitiva -cognitivo-emocional- del atrayente valor ético de la solidaridad para la justicia, la toma de decisiones prácticas para una praxis de la justicia en la vida cotidiana de un ciudadano corriente. Pero el tema de este artículo es llamar la atención sobre el papel de la sensibilidad y los sentimientos como fundamentos para la praxis de la justicia.

$\mathrm{Y}$ es motivo de satisfacción que un sociólogo tan relevante y científico como Manuel Castells haya mostrado con tanta claridad -deslizándose desde lo sociológico hacia lo psicológico-la importancia de las vivencias sensoriales y emocionales sanas para contribuir a la transformación humanizadora de la sociedad.

\section{Definición de solidaridad para la justicia}

Aquí se entenderá por solidaridad para la justicia social:

"la actitud que, a partir del sentimiento de compasión y de indignación ante los daños ocasionados por conductas injustas, y de la toma de conciencia de la responsabilidad personal para la contribución al bien común, experimenta ideales de cooperación social y de actuaciones altruistas para 
contribuir a la promoción y defensa de los derechos humanos, en una lucha por el logro simultáneo de una mayor libertad y justicia en beneficio de todos" (Rosal, 2012, p. 231).

\section{Contribución de la sensibilidad}

Una persona con suficiente fluidez en cuanto a receptividad sensorial sabrá prestar atención para ver (contemplar) y escuchar los sufrimientos que padecen individuos y colectivos que son víctimas de actuaciones o situaciones injustas. Cualquier ciudadano o ciudadana dispone actualmente de muchos más recursos que hace apenas un siglo, para darse cuenta sensorialmente de estas desgracias, en comparación con lo que se podía percibir en épocas pasadas. Por la televisión, y por internet, tiene la posibilidad y facilidad de percibir a gente que padece las consecuencias dolorosas de injusticias provocadas por individuos -especialmente los que tienen poder económico o político-y por estructuras sociales, económicas o políticas que obstaculizan la igualdad en la vivencia de los derechos humanos por parte de los ciudadanos. Véase un ejemplo de información sobre el hecho de las desigualdades injustas que ocurren en el mundo: unos párrafos de la introducción de un libro de Díaz-Salazar. Aparte de poder recibir esta información escrita, cualquier persona tendrá oportunidades de ver con sus propios ojos y escuchar con sus oídos -por televisión, o por internet- ejemplos de individuos de los que se informa en estos párrafos. Ante estas percepciones, si tiene una buena receptividad sensorial, no permanecerá impasible.

"conviene, no obstante, tener presente que cada año mueren de hambre en el mundo 40 millones de personas (toda la población de España en un año) y cada día mueren de hambre 100.000 personas, de las cuales 35.000 son menores de 5 años. En la actualidad, existen en el mundo más de 1.300 millones de pobres, 1.200 millones de personas sin acceso a ningún servicio de salud (es decir, el equivalente a 30 países con el mismo volumen de población que España), 1.300 millones de seres humanos sin acceso a agua potable, 860 millones de analfabetos. Los 3.000 millones de personas que pueblan los países más pobres sólo disponen del 5,4\% del ingreso mundial total, lo que representa unos recursos inferiores al PNB de Francia (57 millones de habitantes). Todo el África subsahariana (unos 565 millones de personas) dispone de algo menos del 1\% del ingreso mundial, lo cual es igual a tener menos de la mitad de los ingresos del Estado norteamericano de Texas. Los países ricos del Norte, que no llegan a representar ni siquiera una cuarta parte de la población mundial, consumen el $70 \%$ de la energía mundial, el $75 \%$ de los metales, el $85 \%$ de la madera y el $60 \%$ de los alimentos. El consumo energético que representa la circulación de turismos en la parte occidental de Alemania, equivalente a unos 40 millones de toneladas de carbón por año, es igual al consumo total de energía de los habitantes de África negra. Es necesario recordar que 
todos los habitantes de la unión Europea, EE.UU., Canadá, Japón, Australia y Nueva Zelanda sólo constituyen el 14\% de la población mundial, esto es, algo menos que toda la población de la India, que representa el 16\% de la población mundial. Las personas que habitamos en los países de la Unión Europea sólo somos el 6,5\% de la población del mundo.

El desconocimiento y, sobre todo, el olvido de esta realidad-que por otro lado se impone con manifestaciones constantes y dramáticas-es el que acompaña la baja intensidad de las políticas y acciones de solidaridad internacional. Especialmente cuando se regresa de algún país empobrecido, se tiene la sensación de que el Norte está ciego y dormido, reposando en un "sueño de cruel inhumanidad" (Jon Sobrino). Y contra este sueño del Norte hay que levantar un movimiento de insumisión a favor del Sur. No podemos consentir que una minoría del $14 \%$ de la humanidad -con islotes ciertamente de pobreza- esté instalada en la cultura de la satisfacción producida por la sociedad de consumo, mientras que la gran mayoría de los habitantes del planeta Tierra están sometidos a la dictadura de la pobreza" (Díaz-Salazar, 1996, pp. 16s.).

Estos años, sin salir de nuestra ciudad, y estar viendo a muchas personas -mayoría inmigrados- que van con un carrito a recoger material del interior de los containers - unos recogen papeles, otros metales, etc. - para poderlos vender por unos pocos euros. La persona sensible evitará acostumbrarse a ver esta desgracia como algo normal. Y al anochecer, en algunos rincones de la ciudad, se puede fácilmente observar que algunos indigentes están instalándose como pueden, con unos cartones y, en el mejor de los casos con una manta, para pasar la noche en el exterior, aunque sea en el invierno, porque no hay plazas disponibles en los albergues, o porque les ha ocurrido que en algunos les han robado parte de lo poco que arrastran con ellos. También muchos de ellos, a pesar del valioso folleto actualizado anualmente por la Comunidad de San Egidio (de 218 páginas) sobre todos los recursos existentes en Barcelona, desconocen la dirección de más de cincuenta lugares donde pueden encontrar comida gratis, los aproximadamente veinte albergues donde pueden probar si hay plazas disponibles, los trece lugares donde pueden ducharse, los locales -principalmente parroquias- donde pueden obtener ropa gratis, o aquéllos en los que les pueden ofrecer ayuda legal, y así sucesivamente.

\section{Trastornos en la sensibilidad}

Si se plantea el problema de los trastornos psicológicos que pueden obstaculizar la actitud solidaria, procede iniciarse por los de la sensibilidad, de los que pueden destacarse los siguientes: 
a) Bloqueo externo deliberado: supresión de información sensorial concreta

Se da aquí no propiamente con un problema psicológico del sujeto, sino con un entorno ambiental en el que se evita que se puedan percibir las actuaciones individuales o estructurales que causan injusticias, con el consiguiente sufrimiento de las víctimas. Ahora bien, la persona puede ser responsable de haber buscado o consentido este ocultamiento, con la finalidad -consciente o inconsciente- de inhibir sentimientos sanos de culpa (no son escasas las personas que han decidido no leer periódicos y escuchar informativos para no ponerse de malhumor). Se dará con más frecuencia en los casos de trastorno de la personalidad evitativo o por dependencia. Cuando tal patología no esté implicada, o sólo en parte, habrá que reconocer una responsabilidad moral.

\section{b) Dispersión externa: exceso de estímulos ambientales}

$\mathrm{Al}$ igual que en el caso anterior, para que se trate de un problema del sujeto, y no sólo de una circunstancia ambiental, se requiere que el sujeto sea responsable al menos parcial de su inserción en este ambiente. Cuando, por el contrario, este ambiente le viene impuesto con muy poco margen de libertad de elección, se da un claro peligro de conducir a trastornos de adaptación.

Una sucesiva multiplicación de informaciones y noticias -por televisión, por internet, u observable directamente transitando por las calles-que muestran señales de sufrimiento en víctimas de injusticias, pueden conducir a una especie de desensibilización sistemática en el ciudadano observador. Puede ir dando pie a un gradual amortiguamiento o desaparición de la capacidad de reacción emocional, a vivenciar esas situaciones como algo normal, que apenas llaman la atención.

Este problema puede dar lugar también al de la atención dispersa, por el que la persona se incapacita para centrar la atención en un hecho o sujeto, que -para el tema que nos ocupa- se relacionaría con la injusticia.

\section{c) Falta de atención a elementos que aportan información relevante}

Aquí se da, no propiamente con un problema de receptividad sensorial, sino de filtración de sensaciones. Pero no se trata de un proceso saludable de filtración -necesario para una conducta sana, concentrada y no estresada- sino de un "punto ciego", que no le permite al sujeto obtener un significado congruente o una ubicación correcta por falta de visión panorámica. Expresándonos con términos de Análisis Transaccional, podrá tratarse con frecuencia de un "mandato de guión" que impida conectar con sensaciones que expresen sufrimientos -con tristeza, o miedo, o rabia- por parte de víctimas de injusticias.

\section{Contribución de los procesos afectivos}

Se pueden señalar algunos sentimientos que son requisitos integrantes de esta actitud, recogidos del libro sobre Valores éticos o fuerzas que dan sentido a la vida (2012, pp. 231). 
a) El sentimiento de tristeza ante las desgracias humanas, como el hambre padecida por un porcentaje importante de la población mundial; la muerte de millones de niños en el Tercer Mundo por imposibilidad de pagar las vacunas o por falta de centros de atención médica; la necesidad de vivir y dormir a la intemperie por falta de recursos para pagar un alquiler; los encarcelamientos injustificados por falta de libertades democráticas o por errores judiciales; la lapidación de mujeres por denuncias de adulterio en algunos países musulmanes, o el desfiguramiento de sus rostros por ácidos, al haber sido violadas y considerarse deshonrada la familia; los periódicos asesinatos a creyentes religiosos -principalmente cristianos- y destrucciones o incendios de sus templos por no admitir la libertad religiosa, las violaciones de mujeres, principalmente durante las guerras. La relación se podría alargar mucho más, pero baste lo mencionado, como muestra representativa de injusticias causantes de sufrimiento y existentes en la actualidad.

Ante estos hechos, que desde que existe la televisión se pueden hacer visibles para todos, la persona con suficiente sensibilidad y fluidez emocional experimentará tristeza en forma de compasión -si tiene cierta capacidad de ponerse en la piel de los otros, de intuición empática- y también indignación ante las injusticias causantes de estas desgracias, por acción o por omisión. Tanto la compasión como la indignación son dos sentimientos básicos para la posibilidad de la actitud solidaria. Por ello es aconsejable que la persona dispuesta a cultivar esta virtud se detenga a veces en contemplar o evocar con recogimiento y atención plena estos hechos, en una especie de meditación que le mantenga atenta y despierta a esta realidad humana dolorosa y sus capacidades para la compasión y la indignación nunca lleguen a inhibirse o apagarse.

b) El sentimiento de esperanza es otro sentimiento que es conveniente destacar aquí. La esperanza en que colaborando con otros es posible alcanzar algunos logros para contribuir a un mundo con más paz y bienestar y menos sufrimiento, gracias a una mayor justicia. La meditación contemplativa sobre lo que podría lograrse actuando con iniciativas personales o colaborando con otras, y el consiguiente sentimiento de alegría ante esa posibilidad futura, pueden ayudar a no permanecer pasivo, inhibiendo toda energía movilizadora para una actuación eficaz, en la medida de las propias capacidades y limitaciones.

c) Puede añadirse aquí también el sentimiento de atracción o captación de la belleza moral de un estilo de vida solidario para la justicia. En el último capítulo del libro citado, el autor se adhiere a la interpretación de aquellos filósofos que, como Max Scheler (1921/1948), sitúan como requisito previo a la consolidación de una actitud ética (virtud) la captación de un valor, la comprensión intuitiva sobre su belleza moral, a través del sentimiento, entendido como un proceso afectivocognitivo, a diferencia de una mera emoción o una mera idea. La actual concepción de lo que se entiende por "inteligencia emocional" se puede percibir como un concepto afín al sentimiento según Max Scheler (2003) o Jacobi (Panikkar, 1948), entre otros. 
Por lo tanto, si uno sabe recogerse para vivir lo que se ha descrito en otro capítulo del mismo libro como "escucha interior" y visualizar mentalmente, con ayuda de la fantasía, cómo sería la vida en una sociedad en la que la mayoría de las personas cultivasen la actitud solidaria para la justicia, incluyendo lo que se ha entendido como "amor social" (Messner, 1967, pp. 524-529), será fácil que surja un sentimiento de admiración hacia ese estilo posible de sociedad y aumente la energía personal que impida desentenderse de toda contribución hacia esa meta.

d) Sentimientos de alegría y admiración ante el testimonio de héroes del altruismo y la solidaridad. Todos tienen oportunidades de experimentar estos sentimientos al contemplar y reflexionar sobre la vida de personajes del presente o del pasado, y a veces también sobre personas cercanas, protagonistas de actuaciones admirables por el ejercicio de esta actitud. No sólo se puede evocar a Mahatma Gandhi, Martin Luther King, la madre Teresa de Calcuta, Louis Pasteur, y otros famosos citados en otros capítulos. Son numerosos los que pueden estar a disposición para evocar sus vidas y abrirse a su influencia, permitiendo experimentar un sentimiento de admiración y una aspiración a implicarse en la actitud de la que son modelos de vida. Merece la pena facilitar esto con la ayuda de la lectura de biografías, o el visionado de películas u obras de teatro. Aparte de lo que constituyen biografías, la literatura y el cine pueden ofrecer a veces la narración de trayectorias vitales admirables como testimonios de solidaridad. ¿Quién no salió con un sentimiento profundo de admiración y alegría tras ver la película La lista de Schlinder (Spielberg, Lustig, Molen y Kennedy, 1993), o La vida de los otros (Berg, Wiedmann, Hamm y von Donnersmarck, 2006), por señalar dos ejemplos? ¿No resulta aconsejable practicar, de vez en cuando, unos minutos de recogimiento y meditación, evocando escenas admirables de este tipo de vidas, como vía para la energetización de la capacidad solidaria?

e) Finalmente, se puede considerar también la contribución del sentimiento de temor -quizá no tanto sentimiento como emoción transitoria- ante los peligros de un futuro previsible, si no aumenta el porcentaje de personas solidarias. Cabe también aquí la práctica de meditaciones con ayuda de la visualización mental de imágenes sobre la vida en una sociedad sin apenas personas solidarias. El filósofo Jonas, en su valiosa obra El principio de responsabilidad. Ensayo de una ética para una civilización tecnológica, plantea la importancia de ser conscientes y responsables sobre las consecuencias previsibles de nuestras actuaciones en las generaciones futuras. Implica en la conducta responsable tanto el sentimiento de esperanza como el de temor.

"Al principio de la esperanza oponemos nosotros no el principio del temor, sino el principio de responsabilidad. Pero sin duda el temor forma parte de la responsabilidad tanto como la esperanza; y dado que el rostro que el temor tiene es el menos atractivo e incluso, en algunos círculos, es objeto de un cierto descrédito moral y psicológico, hemos de concederle nuevamente la palabra, pues hoy es más necesario que en otras épocas en las que, 
dada la confianza existente en la buena marcha de los asuntos humanos, podía ser despreciado como una debilidad propia de individuos pusilánimes y medrosos" (Jonas, 1995, p. 356).

\section{Trastornos emocionales}

Pasando a identificar posibles trastornos emocionales que obstaculizan la vivencia solidaria, procede destacar los cinco siguientes:

\section{a) Emociones prohibidas}

Problema presente en personas que tienen "prohibido" experimentar o expresar alguna de las emociones $-\mathrm{y}$ correspondientes sentimientos-señalados en el apartado anterior y, con mayor razón, en aquellos que padecen las consecuencias de esta "prohibición" inconsciente respecto al conjunto de las emociones. Este estilo de persona fría, sin calidez emocional, se da preferentemente en quienes padecen los trastornos de personalidad esquizoide y antisocial. Algo menos en la personalidad obsesivo-compulsiva. Pero no sólo en éstos. No siempre, en el origen de esta conducta emocionalmente fría, o en la inhibición, en especial de sentimientos de compasión y de indignación se encuentra la influencia recibida en la infancia del mensaje "No sientas" - como se señala en el Análisis Transaccional de Berne, a partir de un estilo de cultura, o grupo familiar, o figura parental. A veces puede ocurrir lo contrario, cuando constituye propiamente una reacción de rebelión frente a unos mensajes culturales, familiares o parentales, que imponían que "hay que sentir continua e intensamente", o que se caracterizaban por una vivencia descontrolada de las emociones. Cualesquiera que sean las influencias que contribuyeron a la gestación -normalmente inconsciente- de una decisión del "guión de la vida", del tipo "no sientas", el hecho es que quien viva sometido a sus consecuencias inhibirá toda experiencia y expresión de estos sentimientos, obstaculizando con ello el cultivo de la actitud solidaria.

\section{b) Falsa identificación por proyección en el presente de una situación pasada}

Aquí no se trata de un bloqueo, sino de una distorsión. A partir de ella se puede producir un sentimiento de compasión, o de indignación, inadecuados para la situación real. Unos jóvenes que conservan en su memoria experiencias dolorosas por actuaciones que percibieron como injustas por parte de su padre-que acostumbraba a vestirse de una determinada manera-, pueden tender a reaccionar con indignación injustificada respecto a todo representante de la autoridad-académica, cultural, política, etc.- que vista de una forma semejante. Personas que conservaban en su memoria frustraciones debidas a un prolongado aplazamiento del retorno a un gobierno democrático, producido por cerca de cuarenta años de franquismo, no era fácil que pudiesen confiar en una persona como Adolfo Suárez -ex-dirigente falangista- como líder posible de la transición democrática. Los ahora unánimemente valorados méritos de este político, reconocidos internacionalmente, tardaron 
mucho en cambiar los sentimientos negativos de indignación hacia él de quienes cayeron, inconscientemente, en una "falsa identificación por proyección en el presente de una situación pasada. Sentimientos de indignación -aunque contenidos- que todavía se expresan de vez en cuando en quienes devalúan los grandes logros de su liderazgo de la transición.

\section{c) Descontrol emocional}

Este problema da lugar a que la emocionalidad de la persona -sea en forma de sentimientos de comprensión, o miedo, o indignación, o esperanza (que son los que aquí interesan) - le desborde e invalide el funcionamiento de los consiguientes procesos cognitivos y volitivos. Quien padece este problema se incapacita para acceder a sus recursos racionales y autolimita su comportamiento.

En el caso del Movimiento de los Indignados, este tipo de distorsión emocional puede conducir, por ejemplo, a episodios maníacos (por descontrol de la esperanza, la alegría, o la rabia); o descontrol de la rabia en personalidades esquizoides, u obsesivas, o antisociales.

A veces su origen puede encontrarse en la educación recibida en la infancia, según la cual el protagonista de una indignación ha aprendido que si se descontrola suficientemente logrará lo que quiere. El niño aprendió que si no le daban lo que deseaba por las buenas, siempre podía montar una pataleta para conseguirlo. Probablemente esta pueda ser una de las causas psicológicas de las actuaciones de esos grupos minoritarios violentos, que van destruyendo todo lo que encuentran escaparates de comercios, coches, containers, farolas, etc.- malogrando los efectos de una manifestación o concentración pacífica del Movimiento de Indignados $\mathrm{u}$ otros similares.

\section{d) Desplazamiento de la afectividad hacia otros niveles de la personalidad}

Aquí se produce una desviación de la energía del caudal afectivo hacia otras áreas como la somática, mediante la somatización o la agitación motora; o bien mediante procesos mentales de tipo racionalizador o pensamiento obsesivoide. Así puede ocurrir, por ejemplo, en quienes padezcan los trastornos de personalidad evitativa u obsesiva, pero no sólo en estos casos.

De hecho, en estos casos, el fluir emocional queda detenido o trastocado. En lugar de la vivencia de emociones o sentimientos profundos -los diversos que he señalado en el Movimiento de los Indignados- aquí sólo se produce agitación práxica, o somatización, o agitación mental. Sin embargo, un funcionamiento sano y fructífero del Movimiento de Indignados y, en general, del dinamismo de todo individuo o colectivo movilizado hacia la solidaridad para la justicia, requiere la vivencia profunda de los sentimientos indicados. Y este problema implica la inhibición de los mismos, o su represión. 
e) Distorsión como consecuencia de una falsa identificación cognitiva

Aquí, como se indica en su denominación, la base de la distorsión emocional se encuentra en el error interpretativo de la fase de identificación cognitiva. Puede estar presente en diversos síndromes y trastornos de la personalidad, y de forma espectacular en momentos de las crisis psicóticas y de la personalidad esquizotípica. De ahí la conveniencia de evitar que personas con estas dolencias se integren en grupos con iniciativas a favor de la justicia, ya que su falta de salud mental puede malograr proyectos valiosos. Conviene evitar que se integren en grupos humanos con proyectos valiosos y solidarios a favor de la justicia personas que se dejan influir excesivamente por prejuicios, proyecciones y generalizaciones sin base objetiva. $\mathrm{O}$ por personas insanamente condicionadas por "posiciones vitales" (Berne, 1974) gravemente distorsionantes de la realidad, de los tipos "Yo estoy bien, tú estás mal", "Yo estoy mal, tú estás mal", "Yo estoy mal, tú estás bien", vivenciadas como individuos y también como colectivo en el que uno se siente implicado. Estas "posiciones vitales" insanas que aparecen más de la cuenta en las relaciones y enfrentamientos entre los partidos políticos, sería lamentable que también malograse los estilos de actuación a favor de la justicia de colectivos inicialmente sanos y bienhechores.

\section{La capacidad valorativa de la actitud solidaria}

Tras los procesos sensoriales y emocionales, corresponde la implicación de la capacidad valorativa, en la cual cabe también la presencia de trastornos que impiden la vivencia solidaria.

Está claro que para reflexionar sobre procesos psicológicos -y sus posibles problemas- que pueden intervenir en la vivencia y praxis de la solidaridad para la justicia -como de cualquier otro valor ético- la fase del ciclo de la experiencia más directamente implicada en ello -según la Psicoterapia Integradora Humanista- es la fase de la valoración. Pero este escrito se limitará casi sólo a nombrar los posibles problemas que obstaculizarían la praxis de este valor. Pues el tema del artículo se centra sólo en los procesos sensoriales y emocionales implicados, que corresponden a tres fases anteriores del fluir vital. Tampoco se detendrá en los problemas de la fase cognitiva, que son importantes en la vivencia de este valor, porque el espacio disponible no lo permite.

Cuando hablamos de capacidad valorativa entendemos la capacidad de discernir-en una situación determinada en la que el sujeto experimenta normalmente varias motivaciones o tendencias-cuál es la que en esa situación ve conveniente considerar prioritaria por su importancia, o tal vez por su urgencia. Este discernimiento o visión se llevará a cabo normalmente por la vía de lo que Max Scheler denominó "intuición emocional". Se trata por consiguiente de una actividad psicológica en la que se integran procesos afectivos y cognitivos.

De las varias motivaciones o tendencias que conducen al sujeto hacia el ejercicio de diversas actitudes o conductas, el que disponga de capacidad valorativa 
sabrá discernir -normalmente por intuición emocional, o en algunos casos por reflexión razonada- cuáles de aquéllas favorecen su proceso de crecimiento personal (o autorrealización) y cuáles lo obstaculizan. No se pretende decir que en una determinada situación, considerada en abstracto, sólo haya una posible motivación (con el acompañamiento de actitudes y conductas) discernible como valiosa. Normalmente serán varias. Pero dado el carácter singular e irrepetible de toda existencia humana, como también lo peculiar de todo proyecto existencial (aunque normalmente sólo implícito), cabrá pensar en que pueda captarse la mayor relevancia o valor de una de las posibilidades.

Respecto a cualquiera de las áreas que componen toda existencia humana es beneficioso disponer de una capacidad valorativa fluida. Al decir "fluida" se entiende, en el modelo psicoterapéutico de la Psicoterapia Integradora, una experiencia valorativa exenta de posibles formas de bloqueo, dispersión o distorsión de sus manifestaciones. Merecen ser destacadas algunas áreas de la vida en las que resulta especialmente conveniente el cultivo de dicha capacidad, para poder diferenciar lo humanizador de lo deshumanizador.

Estas áreas son:

a) La experiencia del amor en sus diversas clases: de relación de pareja, paternofilial, de amistad, de compañeros en proyectos basados en metamotivaciones. etc.

b) La experiencia humana del trabajo, no sólo el profesional.

c) La experiencia de la ciudadanía y la participación política.

d) Las experiencias en relación con la ciencia, el arte, o la filosofía.

e) La experiencia de la administración de los propios recursos económicos.

f) La experiencia de la vinculación a una cosmovisión religiosa, o agnóstica $o$ atea.

g) La experiencia del ocio humanizador.

El tema de este artículo afecta principalmente a las áreas c) y e).

Teniendo presenta la eticidad implicada en el concepto de crecimiento psicológico personal (quizá también habría que hablar de su esteticidad), siguiendo un enfoque frommiano de ética psicológica humanista, el autor se ha detenido en otros lugares (Rosal 2003, 2012; Rosal y Gimeno-Bayón 2011) en la descripción y justificación de veintidós valores éticos, como favorecedores del crecimiento personal.

De los diecinueve problemas que identificados en la fase valorativa del modelo de la Psicoterapia Integradora Humanista aquí solo se van a nombrar los ocho que pueden destacarse más, como obstaculizadores de la solidaridad para la justicia.

Bloqueos posibles que obstaculicen la vivencia -y consiguiente praxis- de la solidaridad pueden estar causados por los problemas siguientes:

- Frigidez valorativa

- Fobia al compromiso de valores 
- Sumisión a la presión de grupos amorales

- Autoprohibición del sentimiento de culpa

Respecto a formas de vivencia dispersa o distorsionada de la fase valorativa, es conveniente destacar los siguientes problemas:

- Fragmentación valorativa

- Valoración invertida

- Valoración por confluencia o rebelión afectiva

- Prejuicio moral

\section{Cinco formas distorsionadas de solidaridad para la justicia}

a) Legalismo: implica los bloqueos de la fase valorativa denominados "heteronomía" y "dogmatismo", y la distorsión valorativa "conciencia inmadura" correspondiente a la segunda etapa convencional del desarrollo moral según Kohlberg (1982). Tal distorsión es más frecuente en la personalidad obsesivo-compulsiva.

b) Solidaridad reduccionista (cuando se ejercita únicamente respecto a un partido político, o una clase social, o la propia nación o cualquier otro colectivo humano, actuando insolidariamente respecto a los otros): tiene relación con la distorsión valorativa denominada "Fragmentación valorativa". Más frecuente en la personalidad pasivo-agresiva y en la antisocial.

c) Cumplimiento de las leyes justas sólo por miedo a la sanción: constituye una distorsión valorativa que en el modelo se denomina "Conciencia inmadura" y, en este caso, corresponde a la fase primera del desarrollo moral según Kohlberg (1982) o "conciencia temerosa", más frecuente en las personalidades evitativa, esquizoide y antisocial.

d) Impaciencia solidaria por falta de realismo: corresponde a la dispersión valorativa denominada "inestabilidad valorativa" (la persona no es capaz de mantener su propia valoración durante el tiempo necesario para que sea eficaz). Más frecuente en la personalidad histriónica y antisocial.

e) Actitud revolucionaria violenta

No han sido pocos, a lo largo de la historia, los líderes de revoluciones violentas que, con la colaboración entusiasta de sus seguidores, han perseguido fines aparentemente justos, pero con medios gravemente injustos. En este sentido puede compararse la Revolución Francesa, con medios extremadamente violentos, a base de llevar a la guillotina a miles de ciudadanos inocentes, hasta acabar matando incluso a varios de los que habían sido los cerebros de la revolución, en comparación con las revoluciones anglosajonas no violentas, sin derramamiento de sangre, o con la revolución no violenta de Gandhi, logrando la independencia de la India. La más violenta en la historia de las revoluciones fue la liderada por Lenin, y continuada por Stalin. Son cerca de cien millones los muertos a causa de dicha revolución, de los cuales sesenta y cinco millones murieron en China y veinte 
millones en la URSS, aparte de los asesinados en otros países.

Nikolai Berdiaev (1874-1948) fue el primer intelectual ruso de prestigio que, a pesar de pertenecer a una familia de la aristocracia, promovió la lucha contra el zarismo para la implantación de un socialismo democrático. El 27 de febrero de 1917 se produjo la revolución democrática en Rusia, con la que quedó derrocado el zar. Esto supuso la inauguración de un sistema democrático parlamentario que, en su comienzo, se tradujo en un gobierno de coalición. Las dificultades internas provocaron cambios en el gobierno, de forma que en septiembre de ese año ya se constituyó un tercer gobierno de coalición, presidido por el socialista democrático Kerenski. Mientras tanto los bolcheviques, liderados por Lenin, prepararon una insurrección armada para tomar el poder. Entre los días 25 y 27 de octubre tuvo lugar el golpe de Estado en Petrogrado y en Moscú, con lo cual se malogró definitivamente el proyecto para Rusia en el que Berdiaev había soñado. Se estableció el sistema totalitario más cruel de la historia que provocó los 104 millones de muertes antes referidas. Se comprende que pasados los años este filósofo ruso escribiese lo siguiente:

"Las revoluciones persiguen grandes fines: la manumisión del hombre de la opresión y de la esclavitud. Los que prepararon la revolución eran hombres heroicos, capaces de sacrificar su vida a una idea. Pero una vez que triunfan, las revoluciones destruyen la libertad, sin dejar la menor huella, desconfían de ella más de cuanto se desconfiaba antes de la revolución, y sus autores, una vez instalados en el poder, se hacen feroces, crueles, y se deshonran derramando sangre humana" (Berdiaev, 1955, p. 241).

\section{Tránsito a la praxis socialmente beneficiosa}

Una vez garantizado un fluir sano de los procesos sensoriales y emocionales, sin olvidar los cognitivos - que aquí no se han considerado-; y una vez captado, con inteligencia emocional, en la fase valorativa, el carácter positivo de los sentimientos de compasión y de indignación respecto a víctimas de injusticias, la persona estará en condiciones de realizar una apropiación personal de este valor, al asumirlo como actitud o virtud ética, como un contenido estable de su personalidad y su conducta.

Entonces se encontrará en las mejores condiciones para:

a) Tomar decisiones concretas para una praxis personal de la solidaridad

b) Movilizar sus recursos para ello

c) Planificar las actuaciones con cierto grado de complejidad

d) Ejecutar las acciones u omisiones para la justicia

Respecto a las omisiones, será capaz de:

\section{$1^{\circ} \quad$ Abstenerse de practicar o colaborar con conductas injustas}

Ejemplos de injusticias contra la verdad son:

- Manipulación de la opinión pública publicando o difundiendo informaciones devaluativas de personas e instituciones, total o parcialmente falsas. 
- Aceptar la propuesta de mentir al actuar como testigo en procesos judiciales.

- Presionar para obtener injustificadamente la baja médica.

- Al impartir cursos o conferencias utilizar fotocopias de esquemas, gráficos, cuadros, tablas, etcétera, sin indicación de la fuente.

- Plagiar escritos.

Ejemplos de injusticias contra la ética económica son:

- Pago de comisiones ilegales para conseguir apoyo para intereses egoístas.

- Traficar con drogas.

- Evadir impuestos.

- Mantenerse cobrando el paro mientras se están cobrando ingresos por un trabajo que no se declara (sin encontrarse en grave necesidad).

- Evitar pagar el IVA siempre que sea posible.

- Evitar dar recibos por servicios profesionales liberales para evitar declarar los ingresos a Hacienda.

- Colocar ahorros en Fondos de Inversión sin averiguar a qué tipo de Empresas se destinará ese capital.

- Perder el tiempo durante la jornada laboral.

- Perder el tiempo como estudiante malgastándose con ello el dinero que dispensa el Estado para subvencionarle, habiéndose podido destinar ese capital a gastos urgentes, por ejemplo, en servicios para el Bienestar Social.

Si se está dispuesto, no sólo a no practicar injusticias, sino tampoco a cooperar directa o indirectamente con ellas, a través de empresas que causan perjuicios a individuos o grupos, o daño medioambiental, se procurará tomar las medidas para evitar colocar ahorros de capital en fondos de inversión que no acrediten abstenerse de invertir el capital en empresas en las que se practiquen lo que, según la clasificación presentada en Bancos Éticos o en Fondos Éticos de Inversión, se entienden como "criterios negativos" (Alsina, 2001, p. 176).

$2^{\circ} \quad$ Abstenerse de consentir costumbres causantes de injusticias

Se citan aquí sólo una parte de las señaladas en el libro Valores éticos (Rosal, 2012).

Puede verse una serie de ejemplos concretos de prácticas de conductas injustas sancionadas por las leyes, parte de las cuales llegan a ser costumbre en algunos ambientes.

- Vender fármacos sin reclamar la presentación de la receta en los casos en que ésta sea obligatoria. El farmacéutico antepone su interés lucrativo al de evitar cometer una imprudencia que pueda ser perjudicial para su cliente y, a la vez, comete la injusticia de competencia desleal con colegas que en otras farmacias se hayan abstenido de venderla. Conseguirá que su cliente simpatice con esta farmacia que se salta esta ley. 
- Sobornar al funcionario correspondiente de un Ayuntamiento para conseguir que sea recalificado un terreno, gracias a lo cual suba notablemente su valor al poder construirse en él viviendas.

- Faltar a la justicia en ocasión de concursos u oposiciones para el nombramiento de profesores titulares universitarios o catedráticos, o en otros tipos de concursos.

- Médicos que recetan medicamentos no necesariamente por ser los más recomendables en un caso determinado, sino por los beneficios que les ofrecen los laboratorios farmacéuticos, los cuales disponen de procedimientos para controlar las recetas de médicos. Los beneficios que ofrecen pueden ser, entre otros, atractivos viajes y estancias en hoteles de lujo con derecho al acompañamiento de las familias.

- Laboratorios farmacéuticos que ofrecen una información algo falsificada, alarmando innecesariamente a las personas calificando de peligrosos síntomas con poca importancia, en vistas a aumentar sus ventas.

- Industrias de producción alimentaria que, cuando se trata de alimentos de los que no puede indicarse la fecha de caducidad - ya que se trata de alimentos de duración indefinida- han creado la costumbre de indicar avisos inquietantes como "consumir preferentemente antes de..." que no tienen ningún fundamento.

Respecto a las acciones, será capaz de:

$3^{\circ} \quad$ Tomar iniciativas eficaces para la promoción y defensa de los derechos humanos, o para colaborar en la reforma de estructuras sociales

Aunque sea sólo un esquema, se transcribe a continuación el que incluye Rafael Díaz Salazar en su libro Redes de Solidaridad Internacional (1996, p. 410).

- La afiliación a las ONGD.

- La inserción en Comités y Plataformas de solidaridad.

- La creación de redes sociales Norte-Sur.

- La implantación de la educación para el desarrollo y la solidaridad internacional en los centros escolares.

- El apoyo al comercio justo.

- La acción internacionalista de los sindicatos.

\section{Contribución de la psicoterapia a la justicia}

No sólo los profesionales honestos, inteligentes y bien formados de la Política, la Economía, el Derecho, etc. tienen en sus manos especiales posibilidades de contribuir eficazmente en una reforma humanizadora de la sociedad. No sólo ellos tienen una responsabilidad relevante de cultivar la actitud de solidaridad para la justicia, y llegar a ser modelos de ella para el conjunto de la ciudadanía.

Los psicoterapeutas -y quizá, con mayor razón, los de la corriente experiencial humanista- tienen unas grandes posibilidades y consiguientes responsabilidades. 
Dada la importante influencia de los problemas psicológicos mencionados, en la debilitación o incapacitación para la actitud solidaria, hay sobradas razones para confiar en que su trabajo de contribución a la salud mental y al crecimiento personal $\mathrm{y}$, en concreto, al favorecimiento de un sano fluir de los procesos sensoriales, emocionales y valorativos de los pacientes a los que se atiende, pueda tener consecuencias beneficiosas no sólo para sus vidas individuales, sino para su influencia social beneficiosa como ciudadanos. Aspirar a que el trabajo psicoterapéutico llegue a tener estas consecuencias puede ser una interesante "metamotivación" -utilizando este término de Abraham Maslow-. Una interesante motivación que fortalezca la capacidad de encontrar sentido a la vida.

\section{Referencias bibliográficas}

Alsina, O. (2001). La banca ética. Molt més que diners. Barcelona, España: FETS.

Berg, Q., Wiedemann, M., Hamm, D. (Productores) y von Donnersmarck, F. H. (Director). (2006). La vida de los otros (Película). Alemania: Wiedeman \& Berg Bayerischer, Arte y Creado Film.

Berne, E. (1974). ¿Qué dice usted después de decir “hola”? Barcelona, España: Grijalbo.

Castells, M. (2005). La Era de la información. Vol. 1: La sociedad red. Madrid, España: Alianza Editorial.

Castells, M. (2006). La Era de la información. Vol. 3: El fin de milenio. Madrid, España: Alianza Editorial.

Castells, M. (2012). Redes de esperanza e indignación. Madrid, España: Alianza Editorial.

Castells, M. (2013). La Era de la información. Vol. 2. El poder de la identidad. Madrid, España: Alianza Editorial.

Díaz Salazar, R. (1996). Redes de solidaridad internacional para derribar el muro Norte-Sur. Madrid, España: HOAC.

Gimeno-Bayón, A. y Rosal, R. (2016). Psicoterapia Integradora Humanista. Manual para el tratamiento de 33 problemas psicosensoriales, cognitivos y emocionales (2a ed.). Bilbao, España: Desclée De Brouwer.

Gimeno-Bayón, A. y Rosal, R. (2017). Manual Práctico de Psicoterapia Integradora Humanista. Tratamiento de 69 problemas en los procesos de valoración, decisión y práxicos. Bilbao, España: Desclée De Brouwer.

Jonas, H. (1995). El principio de responsabilidad. Ensayo de una Ética para la civilización tecnológica. Barcelona, España: Herder.

Kohlberg, L. (1982). Los estadios morales y la moralización: el enfoque cognitivo-evolutivo. Infancia y Aprendizaje, 18, 33-52. https://doi.org/10.1080/02103702.1982.10821935

Maslow, A. (1975). Motivación y personalidad. Barcelona, España: Sagitario.

Messner, J. (1967). Ética social, política y económica a la luz del Derecho Natural. Madrid, España: Rialp.

Pánikkar, R. (1948). F.H. Jacobi y la filosofia del sentimiento. Buenos Aires, Argentina: Sapientia.

Rosal, R. (2003). ¿Qué nos humaniza? ¿Qué nos deshumaniza? Ensayo de una Ética desde la Psicología. Bilbao, España: Desclée de Brouwer.

Rosal, R. (2012). Valores éticos ofuerzas que dan sentido a la vida. Qué son y quiénes los vivieron. Lérida, España: Milenio.

Rosal, R. y Gimeno-Bayón, A. (2011). La búsqueda de la autenticidad. Lérida, España: Milenio.

Scheler, M. (1948). Ética. Nuevo ensayo de fundamentación de un personalismo ético. Tomos 1 y 2. Buenos Aires, Argentina: Revista de Occidente (trabajo original publicado en 1921).

Scheler, M. (2003). Gramática de los sentimientos. Lo emocional como fundamento de la Ética. Barcelona, España: Crítica.

Spielberg (Productor y Director), S., Lusting, B., Molen, G. R. y Kennedy, K. (Productores). (1993). La lista de Schindler (Película). Estados Unidos: Amblin Entertainment. 